\title{
Meandered Corner Planar Monopole Antenna for UWB Applications
}

\author{
S. Muzahir Abbas ${ }^{1}$, Istaqlal Ahmed ${ }^{1}$, Hamza Nawaz $^{2, *}$, Ilyas Saleem ${ }^{1}$ \\ ${ }^{1}$ Department of Electrical Engineering, CIIT, Islamabad, 44000, Pakistan \\ ${ }^{2}$ Department of Electrical Engineering, NUST-SEECS, Islamabad, 44000, Pakistan
}

\begin{abstract}
In this paper, an ultra-wideband (UWB) planar monopole antenna is proposed whose design is quite simple in profile. The anticipated antenna is composed of a rectangle with corner truncation applied on each corner, with the slits on three truncated corners and a rectangular slot in the middle of patch. The simulated results are obtained using HFSS (High Frequency Structure Simulator) and furthermore the antenna is fabricated on RT Roger Duroid 5880 with the substrate dimensions of $30 \mathrm{~mm} 2$ and the height is $0.787 \mathrm{~mm}$ with relative permittivity of 2.2 . To acquire the maximum bandwidth, a comprehensive parametric study has been carried out to optimize the dimensions of an antenna. Both; the simulated and measured results attests that antenna has wide bandwidth, which ranges from $1.65 \mathrm{GHz}$ to $17.6 \mathrm{GHz}$ and $1.65 \mathrm{GHz}$ to $14.5 \mathrm{GHz}(\mathrm{S} 11<-10)$ respectively, along with fine characteristics like good gain, stable radiation pattern and consistent impedance matching.
\end{abstract}

Keywords UWB, Planar-Monopole, Antenna Design, Meandered Corners, Compact Radiating Receiving Element, Transmission Line Feed

\section{Introduction}

Considering advantages in the field of communication; like high data rate, low cost, better spectral density and immunity to multi path interferences, UWB has successfully attained attention in the world of wireless communication[1-2] and a lot of researches are interested in the development of the ultra-wideband (UWB) antennas. In order to get access to the UWB spectrum, the transmitted system should radiate signals that carry the bandwidth greater than $500 \mathrm{MHz}[3]$. Federal Communication Commission (FCC) has allocated the frequency band from 3.1 to $10.6 \mathrm{GHz}[4]$. UWB technology is preferred to transmit audio and video signals because of its efficiency, so it is anticipated that different computer and electronic companies will soon adopt UWB technology[5-7].

A planar monopole antenna is a well known antenna type. Having a variety of beneficial properties like mechanical durability, conformability, low cross polarized radiations and economical in fabrication, planar monopole antenna has made its way in wireless communication[8-10] as wider bandwidth and adequate impedance matching is frequently achieved by partial ground technique[11-13].

In this paper, a compact UWB planar monopole antenna with transmission line feeding is presented. The antenna has

* Corresponding author:

hamza_nawaz@hotmail.com (Hamza Nawaz)

Published online at http://journal.sapub.org/eee

Copyright (C) 2012 Scientific \& Academic Publishing. All Rights Reserved been truncated and slotted to enhance the bandwidth by keeping the gain secure. The antenna is providing impedance bandwidth of $15.5 \mathrm{GHz}$ ranging from $1.65 \mathrm{GHz}$ to 17.6 GHz, being a solution for UMTS, Wi-Fi, WiMAX and UWB applications. The parameters of the proposed antenna are investigated numerically and validated theoretically as well as experimentally.

\section{Antenna Design}

The design of the proposed UWB planar monopole antenna is shown in Figure 1.

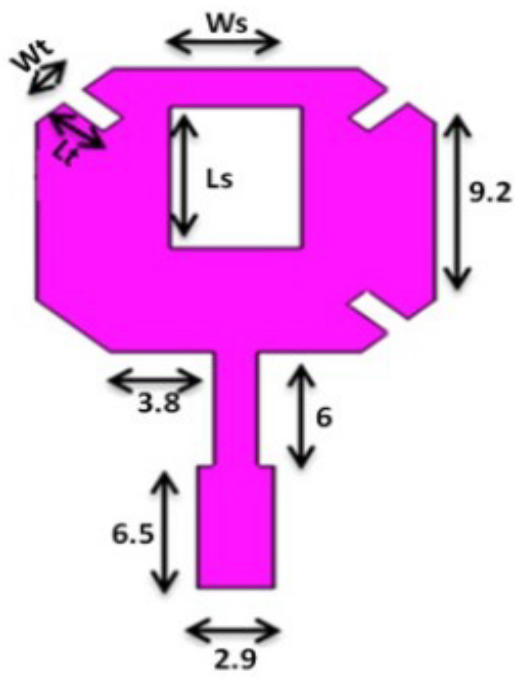

(a) Geometry 


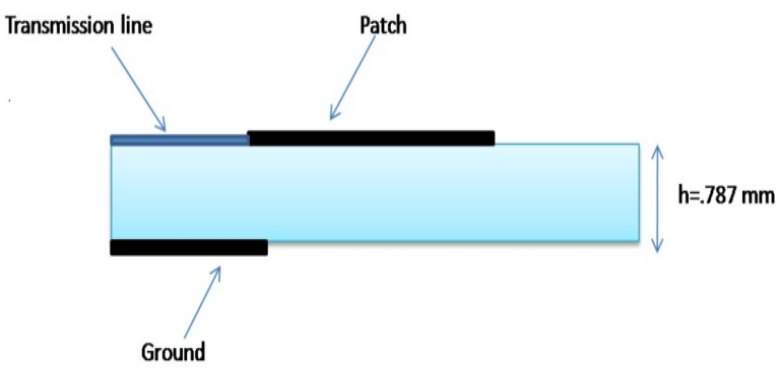

(b) Side View

Figure 1. Design of the proposed antenna

The patch is devised in a manner that the slits imprinted on truncated corners and the central slot improves the spectrum of operating frequency by keeping an adequate gain. The dimensions of the antenna prototype shown in Figure 1(a) are: $\mathrm{W}_{\mathrm{s}}=5 \mathrm{~mm}, \mathrm{~L}_{\mathrm{s}}=7.5 \mathrm{~mm}, \mathrm{~L}_{\mathrm{t}}=2.5 \mathrm{~mm}$ and $\mathrm{W}_{\mathrm{t}}=1 \mathrm{~mm}$. Fabricated antenna is shown in Figure 2.

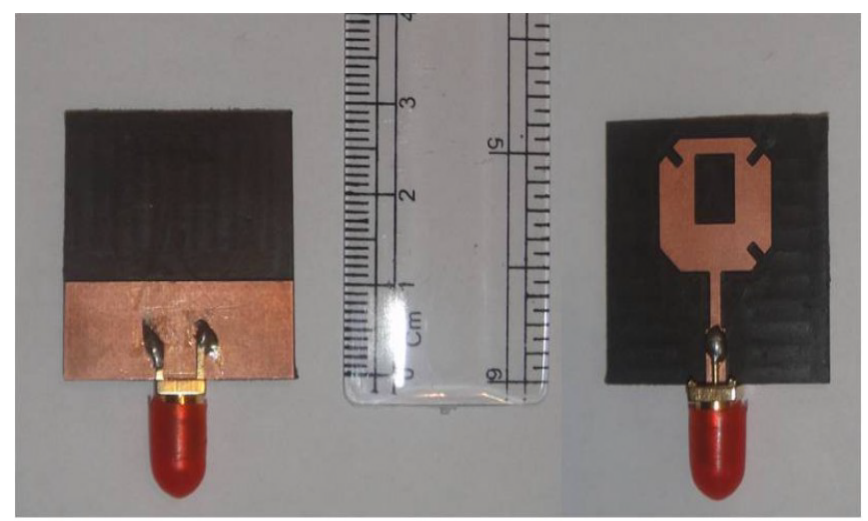

Figure 2. Front and rear view of fabricated prototype

The flow of current from wave port is also prolonged by amending the width of transmission line. Partial ground is deployed on the opposite end to that of planar patch and the size of transmission line and ground plane has been adjusted after acute investigation to achieve good radiation patterns and constant impedance matching of $50 \mathrm{ohm}$.

\section{Results and Analysis}

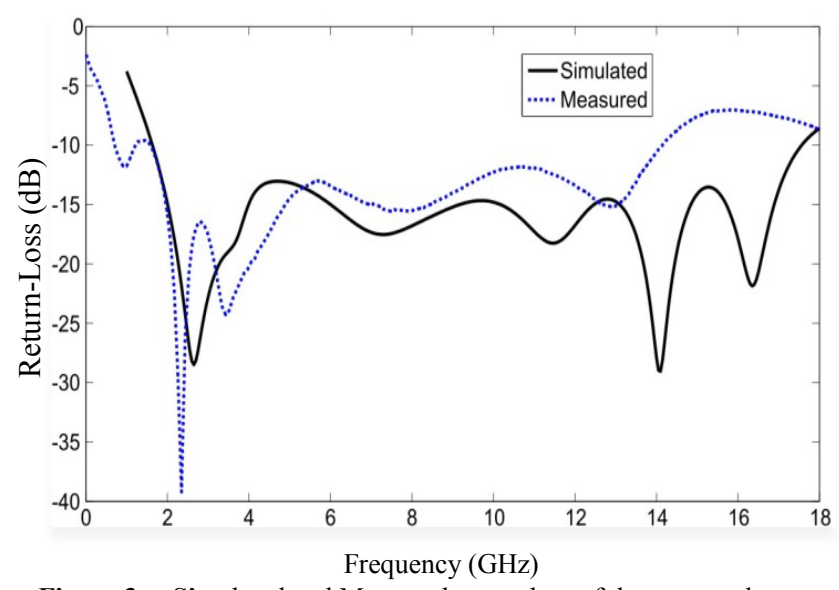

Figure 3. Simulated and Measured return loss of the proposed antenna

All the simulations are carried out using HFSS and the measurement of the antenna was conducted using network analyser of Agilent Technologies, model N5242A. Measured and simulated results of the proposed antenna are depicted in Figure 3 and 4 correspondingly, depicting that the antenna providing efficient bandwidth and suitable behaviour for UWB and even functionality or the low frequencies like that of UMTS $(2.1 \mathrm{GHz})$, Wi-Fi $(2.44 \mathrm{GHz})$ and WiMAX $(3.5 \mathrm{GHz})$.

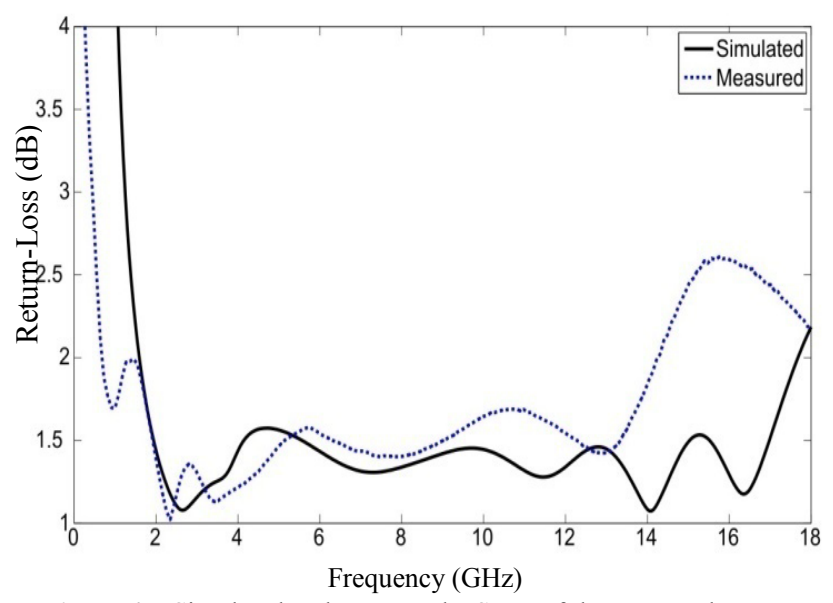

Figure 4. Simulated and Measured VSWR of the proposed antenna

\subsection{Current Distribution}

The simulated current distributions of the antenna at the frequencies of 1.7, 5, 11, $16 \mathrm{GHz}$ are illustrated in Figure 5. The current distribution is relatively stable over the operating frequency range, which indicates that the radiation characteristics will not be affected that much with the change in frequency.

\subsection{Radiation Patterns}

The simulated radiation patterns of the antenna at frequencies of 1.7, 5, 11 and $16 \mathrm{GHz}$ are illustrated in Figure 6. Red and blue patterns depict $\mathrm{H}$-field and E-field of the proposed antenna respectively. Good Omni-directional patterns in xy-plane, yz-plane and zx-plane have been obtained. For achieving the pattern of xy-plane, theta has been set as 90deg for all values of pi. Similarly to show the trend of radiations in yz-plane pi has been set as 90deg for all values of theta and to have radiation trend in zx-plane all values of theta are focused for pi $=0 \mathrm{deg}$. Red and Blue patterns in Figure 6 depict $\mathrm{H}$-field and E-field respectively.

\subsection{Parametric Analysis}

The parametric analysis is carried out to provide engineers with more details of the antenna and a trend adopted by the parameters used in configuration of antenna. The impedance bandwidths of $-10 \mathrm{~dB}$ s-parameters are investigated. Results of the parametric analysis for the various parameters are presented in Figure 7. It has been found that the parameters Ls, Ws, Wt are playing their role in betterment of bandwidth and controlling of return-loss, but the main trend or can say behaviour is set by $\mathrm{Lt}$, which mainly determine the operating band. 
Frequency $=1.7 \mathrm{GHz}$

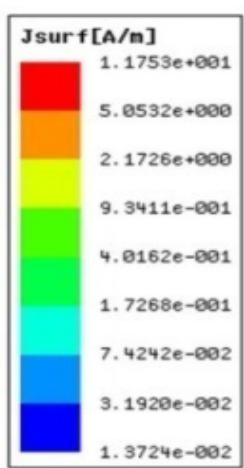

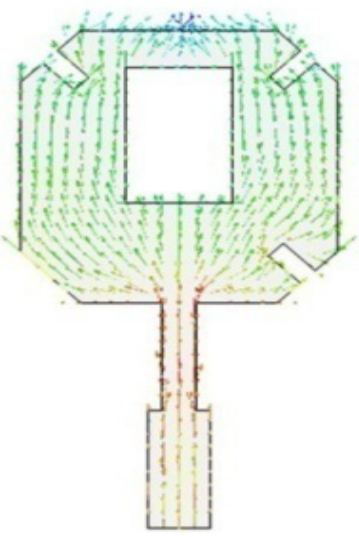

(a)

Frequency $=11 \mathrm{GHz}$

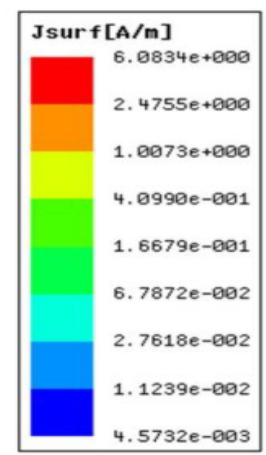

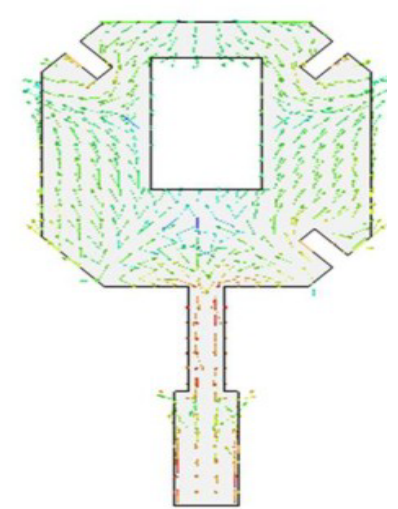

(c)
Frequency $=5 \mathrm{GHz}$
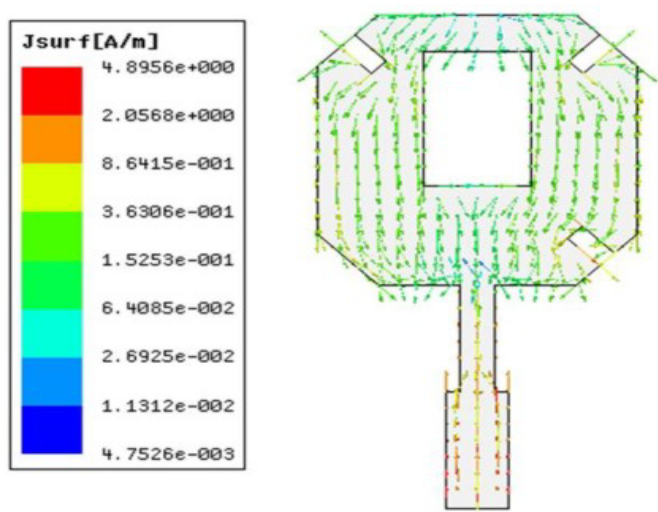

(b)

Frequency $=16 \mathrm{GHz}$
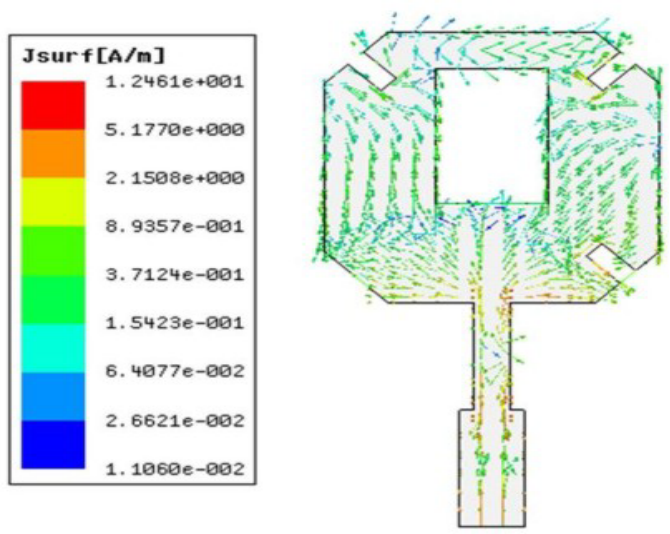

(d)

Figure 5. Distribution of electric current for the proposed antenna at various frequencies

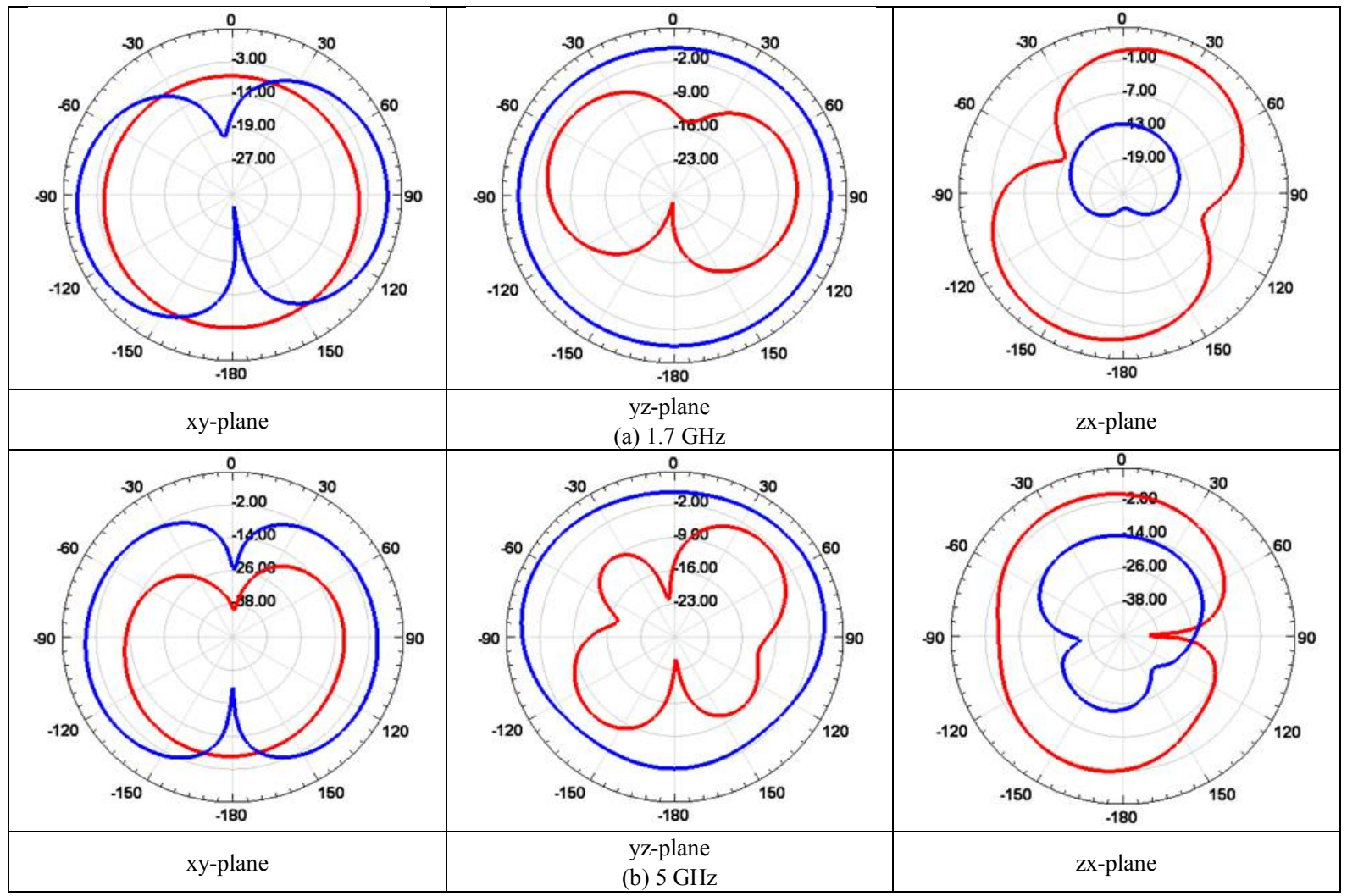




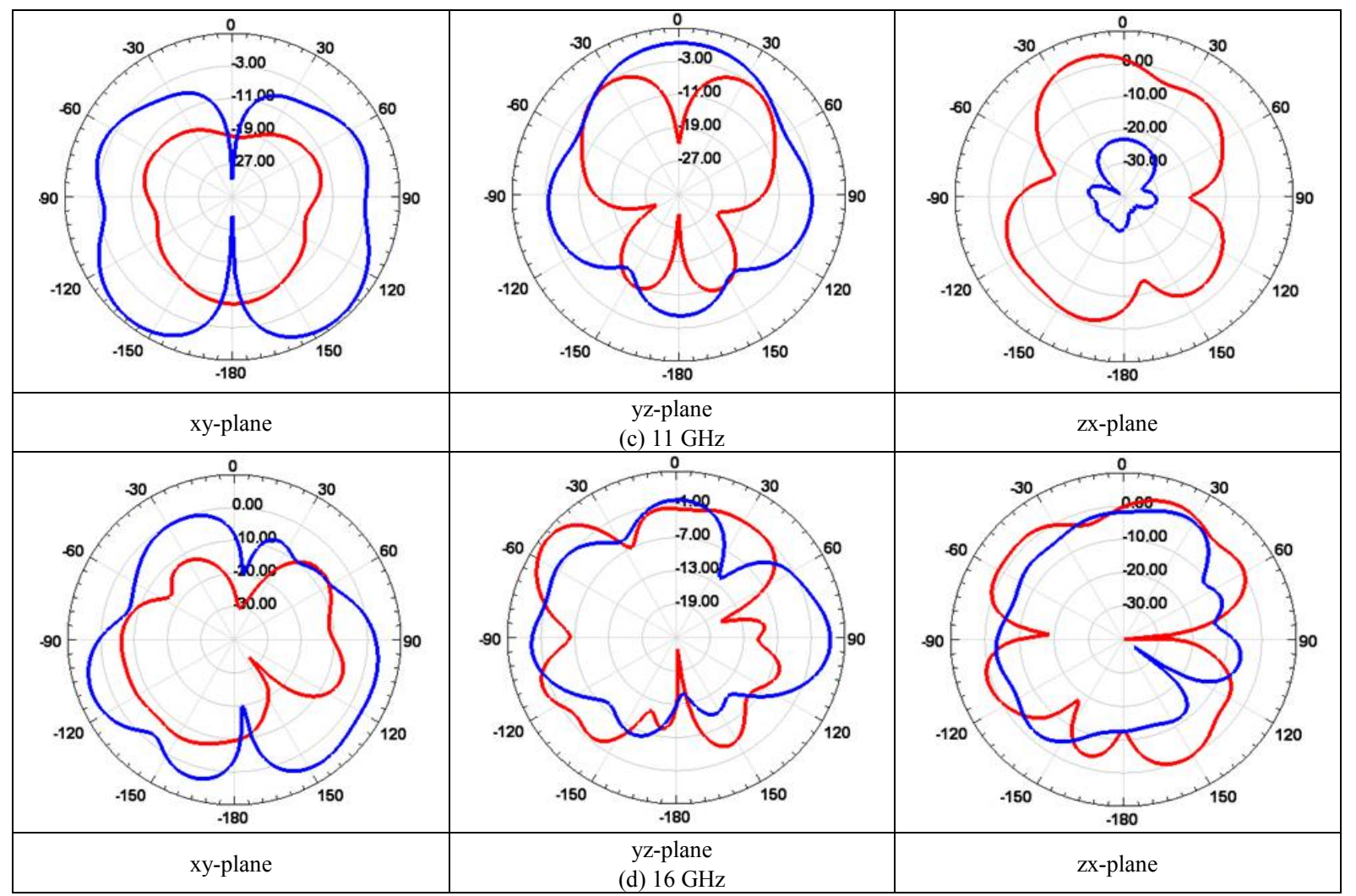

Figure 6. Simulated radiation patterns of the proposed antenna at 1.7, 5, 11 and $16 \mathrm{GHz}$

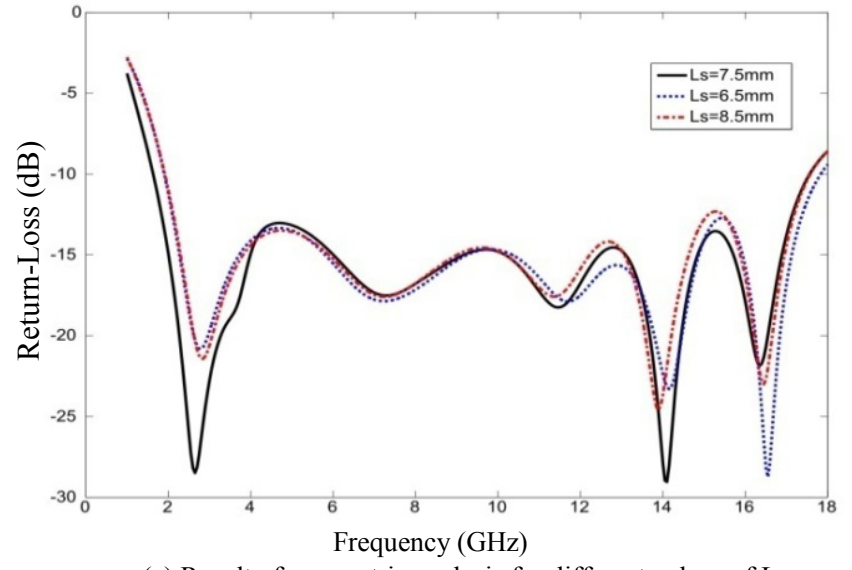

(a) Result of parametric analysis for different values of $\mathrm{L}_{\mathrm{s}}$

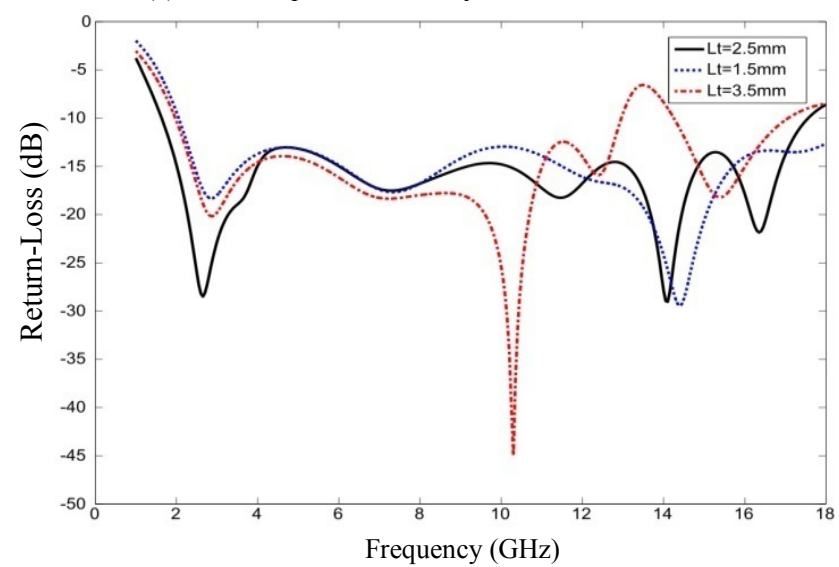

(c) Result of parametric analysis for different values of $\mathrm{L}_{\mathrm{t}}$

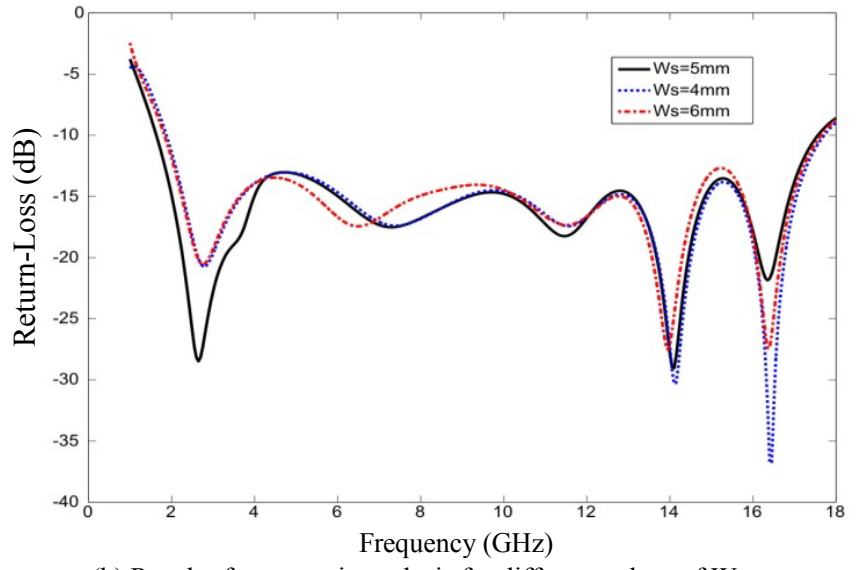

(b) Result of parametric analysis for different values of $\mathrm{W}_{\mathrm{s}}$

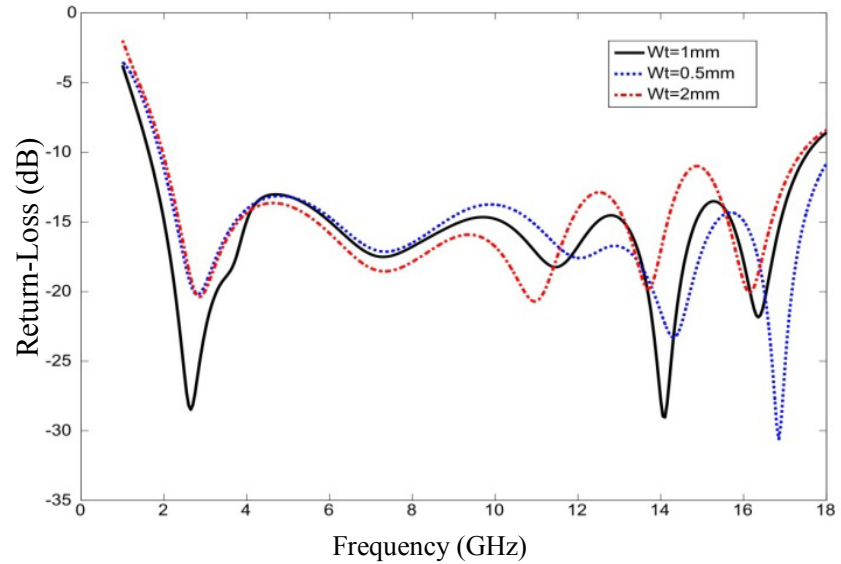

(d) Result of parametric analysis for different values of $\mathrm{W}_{t}$ 


\section{Conclusions}

Antenna design presented is capable for the functionality of UWB. The partial ground plane is used to have fine radiation patterns and addition of slits on truncated corners acclaimed frequency spectrum from $1.65 \mathrm{GHz}$ to $17.6 \mathrm{GHz}$ in HFSS and from $1.65 \mathrm{GHz}$ to $14.5 \mathrm{GHz}$ using network analyser. The parametric study confirmed that the length, width, and position of slits and central slot can control s-parameters. Most of the UWB antennas have difficulty to achieve stable gain with wide band at the same time but, our proposed UWB antenna not only fulfils the FCC assigned frequency band but also capture low frequency bands, despite of being small sized.

\section{REFERENCES}

[1] P. A. Agrawall, G. Kumar, and K. Ray: Wideband planar monopole antennas, IEEE Trans. Antennas Propat., vol. 46, no. 2, pp. 294-295, Feb. 1998.

[2] E. Lee, P. S. Hall, and P. Gardner: Compact wideband planar monopole antenna, Electron. Lett., vol. 35, no. 25, pp. 2157-2158, Dec. 1999.

[3] Schantz, H. G.: A brief history of UWB antennas, IEEE Magazine on Aerospace and Electronic Systems, Vol. 19, No. 4, 22-26, April 2004.

[4] Federal Communications Commission: First report and order, revision of Part 15 of Commission's rule regarding ultra-wideband transmission system FCC 02-48, 22 April 2002.
[5] Schantz, H. G., G. Wolenec, and E. M. Myszka: Frequency-notched UWB antennas, In Proc. IEEE Conf Ultra-Wideband Syst. Technol., pp. 214-218, Nov. 2003.

[6] K. Bahadori, and Y. Rahmat-Samii: A miniaturized elliptic-card UWB antenna with WLAN band rejection for wireless communications, IEEE Trans. Ant. Propagat., vol. 55, pp. 3326-3332, Nov. 2007.

[7] Kerhoff, A. and H. Ling: A parametric study of band-notched UWB planar monopole antenna, In Proc. IEEE Int. Symp. Antennas Propagat., vol. 2, pp. 1768-1771, Jun. 2004.

[8] J. Q. Howell: Microstrip Antennas, in Dig. Int. Symp. Antennas Propagat. Soc., Williamsburg, VA, Dec. 1972, pp. 177-180.

[9] J. Q. Howell: Microstrip Antennas, IEEE Trans. Antennas Propagat., vol. AP-23, no.1, pp. 90-93, Jan. 1975.

[10] C.A. Balanis: Antenna Theory, Analysis and Design, Wiley-Interscience, 2005.

[11] Z. N. Low, J. H. Cheong and C.L. Law: Low-Cost PCB Antenna for UWB Applications, IEEE Antennas and Wireless Propagat. Letter, vol. 4, pp 237-239, 2005.

[12] J.-P. Zhang, Y.-S. Xu and W.-D. Wang: Microstrip-Fed Semi-Elliptical Dipole Antennas for Ultrawideband Communications, IEEE Transactions on Antennas and Propagat., vol. 56, no. 1, pp. 241-244, January 2008.

[13] M. Al-Husseini, A. El-Hajj, and K.Y. Kabalan: A 1.9-13.5 $\mathrm{GHz}$ Low-Cost Microstrip Antenna, in The 2008 International Wireless Communications and Mobile Computing Conference (IWCMC08),Crete Island, Greece, 6-8 August 2008. 